\title{
The Cost Effectiveness of Lisdexamfetamine Dimesylate for the Treatment of Binge Eating Disorder in the USA
}

\author{
Tamás Ágh $^{1}$ - Manjiri Pawaskar ${ }^{2}$ Balázs Nagy ${ }^{1,3}$ - Jean Lachaine ${ }^{4}$. \\ Zoltán Vokó ${ }^{1,3}$
}

Published online: 25 February 2016

(c) The Author(s) 2016. This article is published with open access at Springerlink.com

\begin{abstract}
Background Lisdexamfetamine dimesylate (LDX) demonstrated efficacy in terms of reduced binge eating days per week in adults with binge eating disorder (BED) in two randomized clinical trials (RCTs).

Objective The objective of this study was to evaluate the cost effectiveness of LDX versus no pharmacotherapy (NPT) in adults with BED from a USA healthcare payer's perspective.

Study Design and Methods A decision-analytic Markov cohort model was developed using 1-week cycles and a 52-week time horizon. Markov health states were defined based upon the Diagnostic and Statistical Manual of Mental Disorders, 5th Edition criteria of BED. Model parameter estimates were obtained from RCTs, a survey, and literature. The primary outcome was incremental costeffectiveness ratio (ICER). The analysis assumed a 12-week course of treatment, based upon RCTs' treatment duration. One-way deterministic and probabilistic
\end{abstract}

Electronic supplementary material The online version of this article (doi:10.1007/s40261-016-0381-3) contains supplementary material, which is available to authorized users.

Tamás Ágh

tamas.agh@syreon.eu

1 Syreon Research Institute, 119 Thököly Street, 1146 Budapest, Hungary

2 Shire, 735 Chesterbrook Boulevard, Wayne, PA 19087, USA

3 Department of Health Policy and Health Economics, Faculty of Social Sciences, Eötvös Loránd University, 1/a Pázmány Péter Street, 1117 Budapest, Hungary

4 Faculty of Pharmacy, University of Montreal, 2940 Chemin de la Polytechnique, Montréal, QC H3T 1J4, Canada sensitivity analyses were conducted to assess the robustness of the results.

Results Patients on LDX therapy gained 0.006 quality-adjusted life years (QALY) compared to patients on the NPT arm, while the average total cost was US $\$ 175$ higher for LDX therapy. The estimated ICER for LDX compared with NPT was US $\$ 27,618$ per QALY, which was shown to be cost effective given a willingness-to-pay threshold of US\$50,000. Conclusions Treatment of BED with LDX showed increase in QALYs at an acceptable cost and is considered to be cost effective at the commonly used willingness-topay threshold in the USA. Based on the available evidence, the current model focused on short-term benefits only. There is a need to generate additional scientific evidence supporting long-term benefits of LDX therapy for BED.

\section{Key points for Decision Makers}

Binge eating disorder has a significant, under-served patient population due to the absence of satisfactory medical treatments.

Lisdexamfetamine dimesylate is a novel pharmacotherapy that was recently approved by the United States Food and Drug Administration for the treatment of binge eating disorder.

These results show that lisdexamfetamine dimesylate generates improvement in quality-adjusted life years at an acceptable cost compared with no pharmacotherapy.

Results suggest that lisdexamfetamine dimesylate is a cost-effective treatment for binge eating disorder in the USA. 


\section{Introduction}

Binge eating disorder (BED) is a chronic psychiatric disorder, characterized by recurrent episodes of compulsive overeating (binge eating episodes) during which patients consume larger amounts of food than normal, experience the lack of control and which are not followed by compensatory behaviors (e.g. self-induced vomiting, diuretic or diet pills abuse, or intense exercising) [1]. Binge eating is often rooted in poor body image, use of food to deal with stress, low self-esteem and dysfunctional thoughts [1]. BED appears to affect a broader spectrum of the population than anorexia nervosa and bulimia nervosa; the lifetime prevalence of BED is about 1-2 \% [2-6]. With the association of BED and obesity, this disorder becomes a clinically significant disorder that presents both medical and psychiatric issues that impair the health-related quality of life (HRQoL) and increase healthcare utilization [2, 7].

BED has a large, under-served patient population due to the absence of satisfactory medical treatments. This is also supported by the fact that currently only a minority of patients receive a specific treatment for $\operatorname{BED}[4,7,8]$. Therapies are intended to treat and control the symptoms of $\mathrm{BED}$, such as binge eating, overweight, and the disorderspecific psychopathology [9]. Treatment options of BED include pharmacological and non-pharmacological therapies applied alone or in combination. Studies support the effectiveness of non-pharmacological interventions (i.e. cognitive behavioral therapy, interpersonal psychotherapy, dialectical behavior therapy, and behavioral weight-loss therapy) in the treatment of BED [10]. Nevertheless, nonpharmacological interventions have demonstrated only a minimal impact on weight control in the long term [10], and may not be suitable for people who have more complex mental health needs, or learning difficulties. While some limited scientific evidence suggests that selective serotonin reuptake inhibitors (e.g. fluoxetine) [11-13], serotoninnorepinephrine reuptake inhibitors (e.g. duloxetine) [14], and antiepileptic drugs (e.g. topiramate) $[15,16]$ have an advantage over placebo for achieving reduced binge eating frequency and decreased body weight, none of these drugs is approved for the treatment of BED [17].

Lisdexamfetamine dimesylate (LDX, Vyvanse ${ }^{\circledR}$ ) 50 and $70 \mathrm{mg}$ is a novel pharmacotherapy that was recently approved by the United States Food and Drug Administration (US FDA) for the treatment of adults with BED. LDX demonstrated efficacy versus placebo in decreasing binge eating days per week from baseline in two randomized, placebo-controlled, parallel-group, multicenter studies, with the same design and methods (i.e. SPD489-343 and SPD489-344) [18]. LDX also showed improvement in binge eating-related secondary endpoints (e.g. binge eating episodes per week, the global impressions of BED improvement, 4-week cessation from binge eating, change in body weight, obsessive/compulsive binge eating symptoms, and triglycerides) [18]. LDX may be a first-line drug therapy option in BED with or without psychotherapy, as determined by physicians.

Under budgetary constraints, cost-effectiveness analyses have increasingly been used as a tool to select health interventions for public financing. Cost-effectiveness analysis permits comparing different treatment options upon these health benefits and economic value [19]. The objective of this study was to assess the cost effectiveness of LDX compared with no pharmacotherapy (NPT, placebo) for the treatment of adult BED patients from a US healthcare payer perspective.

\section{Methods}

A decision-analytic Markov cohort model (Microsoft Excel 2010) was designed using a 52-week time horizon to estimate the cost effectiveness of LDX compared with NPT. NPT was represented by placebo in terms of effect. The model was designed from the healthcare payer perspective in the USA, thus only health outcomes [i.e. quality-adjusted life years (QALYs)] and direct medical costs were considered in the analysis. Because of the 52-week time horizon, no discounting was performed. The choice of this relatively short time horizon can be justified by the lack of long-term data (LDX pivotal trials in BED were 12-week long [18]) that could be used to inform the economic model in terms of the long-term benefits of LDX therapy in BED.

The Markov model consisted of seven mutually exclusive health states as presented in Fig. 1 with the duration of each cycle being 1 week. Health states were defined in accordance with Diagnostic and Statistical Manual of Mental Disorders, 5th Edition (DSM-5) criteria [1]. The 1-week cycle length was chosen because this time period was appropriate to determine DSM-5 binge eating behavior severity states [1]. Mortality was not included in this analysis as the time horizon of the model was 52 weeks and there were no data available on the effect of LDX on mortality in BED patients.

The model was used to consider a cohort of 1000 adult BED patients. Gender ratio applied in the analysis was based on US-based population estimates [20] and genderspecific 12-month DSM-5 BED prevalence rates [Kantar Health. VALIDATE study: binge eating disorder final report. 2014. Data on file at Shire; Cossrow N, Russo LJ, Ming EE, Witt EA, Victor TW, Wadden TA. Estimating the prevalence of binge eating disorder in a community sample comparing DSM-IV-TR and DSM-5 criteria. Poster presented at: American Psychiatric Association 167th 


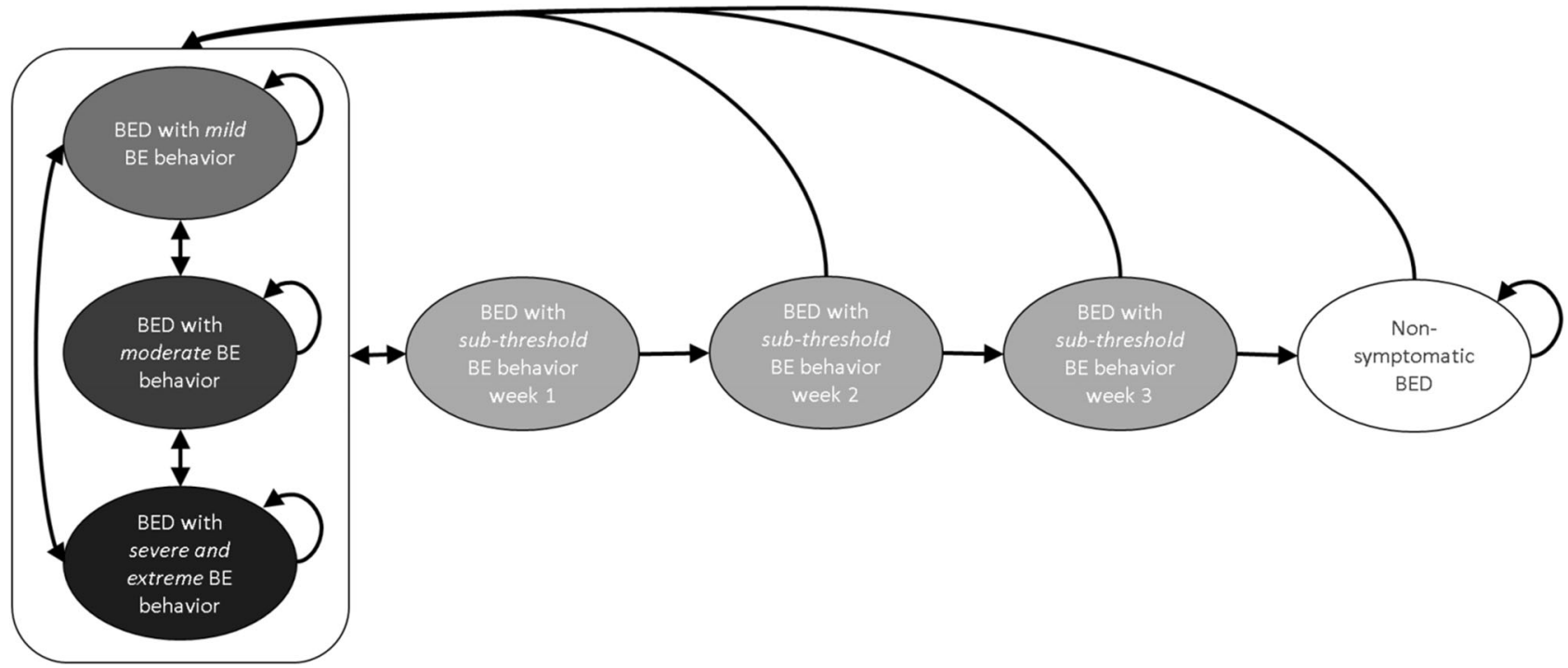

Fig. 1 Structure and patient pathways of the cost-effectiveness model. Non-symptomatic BED: after full criteria for BED were previously met, but binge eating occurs less than once per week for at least 4 weeks; BED with sub-threshold binge eating behavior week 1 , week 2, and week 3: after full criteria for BED were previously met and less than one binge eating episode for 1,2 , or 3 week(s); BED with mild binge eating behavior: after full criteria for BED were

Annual Meeting. May 3-7, 2014. New York, NY]. Binge eating behavior severity characteristics of the patient population entering the model were assumed to match those observed in the Validate Attitudes and Lifestyle Issues in Depression ADHD and Troubles with Eating (VALIDATE) survey [Kantar Health. VALIDATE study: binge eating disorder final report. 2014. Data on file at Shire]. VALIDATE was a self-administered, internet health-based survey completed by US adults, which used a sample source including respondents of the Kantar Health 2012 and 2013 US National Health and Wellness Survey. The survey included questions related to demographics, general health, healthcare utilization, and diagnosed psychiatric disorders, as well as questions designed to assess the DSM-5 criteria for BED. A total of 22,397 respondents completed the VALIDATE survey [Kantar Health. VALIDATE study: binge eating disorder final report. 2014. Data on file at Shire; Cossrow N, Russo LJ, Ming EE, Witt EA, Victor TW, Wadden TA. Estimating the prevalence of binge eating disorder in a community sample comparing DSM-IV-TR and DSM-5 criteria. Poster presented at: American Psychiatric Association 167th Annual Meeting. May 3-7, 2014. New York, NY]. Characteristics of population entering the model are shown in Table 1.

The choice of using NPT (placebo) as comparator is supported by the facts that (1) no comparative data with other intervention exist and there is no ongoing LDX clinical trial with active comparator, (2) no other drug previously met and 1 to 3 binge eating episode(s) per week; BED with moderate binge eating behavior: after full criteria for BED were previously met and more than three to seven binge eating episodes per week; BED with severe and extreme binge eating behavior: after full criteria for BED were previously met and more than seven binge eating episodes per week. $B E$ binge eating, $B E D$ binge eating disorder

Table 1 Patient population entering the model

\begin{tabular}{lc}
\hline Parameters & Values $(\%)$ \\
\hline Female $^{\mathrm{a}}$ & 62.93 \\
Binge eating behavior severity distribution $^{\mathrm{b}}$ & \\
BED with mild binge eating behavior & 51.45 \\
BED with moderate binge eating behavior & 47.09 \\
BED with severe and extreme binge eating behavior & 1.46
\end{tabular}

$B E D$ binge eating disorder

a Data source: US based population estimates (projected for 2015): US Census Bureau [20], gender-specific 12-month BED prevalence rates (DSM-5, projected for the US population): VALIDATE survey [Kantar Health. VALIDATE study: binge eating disorder final report. 2014. Data on file at Shire; Cossrow N, Russo LJ, Ming EE, Witt EA, Victor TW, Wadden TA. Estimating the prevalence of binge eating disorder in a community sample comparing DSM-IV-TR and DSM-5 criteria. Poster presented at: American Psychiatric Association 167th Annual Meeting. May 3-7, 2014. New York, NY]

b Data source: VALIDATE survey [Kantar Health. VALIDATE study: binge eating disorder final report. 2014. Data on file at Shire]

therapy is approved for the treatment of BED in the USA, and (3) currently only a minority of BED patients receive pharmacological and/or non-pharmacological treatment specifically for their eating disorder [2].

There are no real-world data on the expected duration of LDX therapy in BED. In the analysis, the treatment length was set to 12 weeks with steady relapse after 
treatment was completed, which was chosen for the following reasons: (1) in the LDX pivotal clinical trials the treatment period was 12 weeks long [18]; and (2) when conducting this analysis no efficacy data for long-term treatment existed and there were no data on recurrence and remission of BED after the discontinuation of LDX therapy.

Transition probabilities between Markov health states were calculated based on individual binge eating behavior severity data (i.e. number of binge eating episodes in the last week) from the pivotal clinical trials [18] for both LDX and NPT arms. Online Resource 1 depicts the transition probability matrices for LDX and NPT arms. The model assumed steady relapse after LDX treatment was completed, thus after the 12th cycle transition probabilities were equal in both arms. Discontinuation due to adverse events (AEs) on the LDX arm was considered in the analysis.

Utility values were estimated based on the EQ-5D-5L individual patient level data of the pivotal clinical trials [18] by applying the EQ-5D-5L value set developed by EuroQol Group, using US population norms (Table 2).

The model considered two types of costs: drug costs and medical costs (medical costs included resource utilization costs and costs of adverse events). The wholesale acquisition cost of LDX was US\$6.63 per pill for the 50 and $70 \mathrm{mg}$ strengths. Healthcare utilization data were derived from the VALIDATE study [Kantar Health. VALIDATE study: binge eating disorder final report. 2014. Data on file at Shire]. Healthcare utilization could be calculated for the following two health states: (1) non-symptomatic BED (as described previously in Fig. 1), and (2) symptomatic BED (all patients who do not meet the criteria of non-symptomatic BED health state; i.e. BED with sub-threshold binge eating behavior week $1-3$, BED with mild binge eating behavior, BED with moderate binge eating behavior, and BED with severe and extreme binge eating behavior Markov health states). Health service unit costs were derived from the 2012 Medical Expenditure Panel Survey (MEPS) [21]. All cost data applied in the model were inflated to the year of 2013 using US-specific gross domestic product deflator [22]. For weekly healthcare utilization data and health service unit costs, please see Table 3.

Treatment-emergent AEs related to LDX therapy occurring in more than $5 \%$ of subjects in the pivotal clinical trials [18] were considered in the analysis, i.e. dry mouth, insomnia, headache, nausea and decreased appetite (weekly incidence rates of AEs were 0.64, 0.29, 0.13, 0.18, and $0.13 \%$, respectively). Costs of AEs were assumed to be resolved during the cycle in which the $\mathrm{AE}$ took place. Costs of AEs per week associated with LDX therapy were calculated by multiplying the weekly incidence of AEs with cost of family doctor visit (US\$154.62) [22]. Disutilities linked to AEs were considered during the utility estimation of health states [18]. Patients who discontinued therapy were assumed to generate the mean utility and mean cost per week of patients on NPT arm (0.0175 QALY per week, US\$132.05 per week).

By systematically changing the base-case estimates [i.e. each variable by $\pm 10 \%$ (utility values were maximized at 1.00 , thus utility of non-symptomatic BED health state could be increased only by $5.35 \%$; to be able to compare the effect of uncertainty related to utility variables $\pm 5.35 \%$ were applied for all utility variables)], a series of one-way deterministic sensitivity analyses (DSA) was programmed and run through the model to find the most sensitive parameters [23]. Probabilistic sensitivity analysis (PSA) was also performed to account for the simultaneous effect of uncertainty relating to model parameter values; 10,000 model iterations were run by using Monte Carlo simulation. In the PSA, transition probabilities, utilities and $\mathrm{AE}$ incidence rates were sampled from beta distributions, and healthcare utilization frequencies and costs were sampled from gamma distributions. Parameters for sampling distributions were derived from point estimates and standard errors for each variable [24].

Quality-control procedures were performed by a modeler not involved in the model development according to a pre-specified test plan and included both programming validation and the verification of all input data with their original sources. In addition, a series of diagnostic tests were conducted to confirm that the model was correctly applying all formulas.
Table 2 Utility values per Markov health states

\begin{tabular}{ll}
\hline Markov health states & Utility values \\
\hline Non-symptomatic BED & 0.949 \\
BED with sub-threshold binge eating behavior week 1-3 & 0.939 \\
BED with mild binge eating behavior & 0.909 \\
BED with moderate binge eating behavior & 0.886 \\
BED with severe and extreme binge eating behavior & 0.877 \\
\hline
\end{tabular}

$B E D$ binge eating disorder

Data source: SPD489-343 and SPD489-344 clinical trials [18] 
Table 3 Weekly healthcare utilization data and health service unit costs

\begin{tabular}{|c|c|c|c|}
\hline & $\begin{array}{l}\text { Non-symptomatic BED } \\
\text { Mean number of visits per week }\end{array}$ & $\begin{array}{l}\text { Symptomatic BED } \\
\text { Mean number of visits per week }\end{array}$ & $\begin{array}{l}\text { Cost per unit } \\
2013 \text { USD }^{\mathrm{e}}\end{array}$ \\
\hline General internist/family doctor visit & 0.0591 & 0.0921 & $\$ 163.41$ \\
\hline Psychiatrist visit & 0.0061 & 0.0238 & $\$ 157.46$ \\
\hline Psychologist visit & 0.0049 & 0.0171 & $\$ 143.64$ \\
\hline Psychotherapist visit & 0.0117 & 0.0330 & $\$ 143.64$ \\
\hline Nurse practitioner visit & 0.0126 & 0.0247 & $\$ 153.84$ \\
\hline Gynecologist visit (only for women) & 0.0209 & 0.0291 & $\$ 234.50$ \\
\hline Emergency room visit & 0.0054 & 0.0129 & $\$ 517.82$ \\
\hline Hospitalization $^{\mathrm{a}}$ & 0.0035 & 0.0083 & $\$ 12,959.98^{\mathrm{c}}$ \\
\hline
\end{tabular}

$B E D$ binge eating disorder, 2013 USD United States dollar, year 2013

a International Classification of Diseases-Version 9, 307

b Median cost

c Mean (standard deviation) number of nights per hospital event: 3.00 (1.73)

${ }^{\mathrm{d}}$ Data source: VALIDATE survey [Kantar Health. VALIDATE study: binge eating disorder final report. 2014. Data on file at Shire]

e Data source: Medical Expenditure Panel Survey 2012 [22]

\section{Results}

Average direct medical costs per patient incurred over a 52 -week time period were estimated at US $\$ 6867$ for NPT and US\$7042 for LDX, resulting in an incremental total cost of US\$175 for LDX compared with NPT. The estimated QALYs during the 52-week time period was 0.911 and 0.917 for NPT and LDX, respectively. This resulted in an incremental QALY of 0.006, comparing NPT with LDX. Thus, the incremental cost-effectiveness ratio (ICER) with the use of LDX compared to NPT was US\$27,618 per QALY (Table 4).

DSA demonstrated that the model was most sensitive to the utility of 'non-symptomatic BED' health state but responsive to changes in other model parameters. The tornado diagram in Fig. 2 highlights the 25 most sensitive variables on the ICER when base-case estimates were changed by $\pm 10 \%$ (except utility variables which could be changed only by $\pm 5.35 \%$, as utility values were maximized at 1.00).

PSA was undertaken that ran 10,000 model iterations, comparing LDX with NPT. The performed PSA demonstrated that LDX had an $82 \%$ chance of being cost effective in the treatment of BED at a willingness-to-pay threshold of US\$50,000 per QALY [25] (Fig. 3).

\section{Discussion}

This is the first study to examine the cost effectiveness of LDX compared to NPT (placebo) for the treatment of adults with BED in the USA. Results of this Markov model showed that BED patients treated with LDX for 12 weeks had better clinical outcomes [18] at slightly increased costs. The overall ICER was US\$27,618 per QALY suggesting that LDX may be a cost-effective option compared with NPT in adult patients with BED considering a willingness to pay threshold of US\$50,000. These findings can support healthcare payers regarding the efficient allocation of health resources, as cost-effective interventions are highly desirable in improving healthcare system efficiency.

Based on the results of the conducted DSA, the most sensitive input parameter was the utility value of "nonsymptomatic BED' health state; the influence of other model parameters was less marked. A cost-effectiveness acceptability curve was also calculated, showing the probability of cost effectiveness of LDX given varying willingness to pay for a QALY. At the commonly used willingness to pay threshold (US\$50,000) in the USA [26], compared with NPT, LDX had an $82 \%$ chance of being cost effective in BED.

LDX is a novel treatment for BED and when conducting this analysis no long-term efficacy data to estimate its potential long-term benefits in BED, including long-term reduction in body weight and the health consequences of weight reduction (e.g. decrease in the prevalence and the severity of diabetes, hypertension, hypercholesterolemia, heart failure, ischemic heart disease) were available, that may affect the cost effectiveness of LDX in the long run.

Evidence suggests that the budget impact of introducing LDX for the treatment of BED would be modest in the USA [26]. In a budget-impact analysis, the total direct budgetary cost of treating BED within the adult US population without LDX was estimated to be US\$241,699,596 
Table 4 Cost-effectiveness analysis results (US\$)

\begin{tabular}{llll}
\hline Outcome & $\begin{array}{l}\text { Lisdexamfetamine } \\
\text { dimesylate }\end{array}$ & No pharmacotherapy & Difference \\
\hline $\begin{array}{l}\text { Total cost } \\
\text { QALY }\end{array}$ & $\$ 7,041.92$ & $\$ 6,866.52$ & $\$ 175.41$ \\
ICER & 0.9171 & 0.9108 & 0.0064 \\
Average costs per patient & & & $\$ 27,617.56$ \\
$\begin{array}{l}\text { Drug } \\
\text { Primary care }\end{array}$ & $\$ 541.82$ & $\$ 0.00$ & \\
$\begin{array}{l}\text { Out-patient } \\
\text { care }\end{array}$ & $\$ 869.31$ & $\$ 903.66$ & $\$ 541.82$ \\
$\begin{array}{l}\text { Emergency } \\
\text { room }\end{array}$ & $\$ 657.62$ & $\$ 699.43$ & $-\$ 34.35$ \\
$\begin{array}{l}\text { Hospitalization } \\
\text { Adverse events }\end{array}$ & $\$ 288.58$ & $\$ 307.12$ & $-\$ 41.80$ \\
\hline
\end{tabular}

ICER incremental cost-effectiveness ratio, $Q A L Y$ quality-adjusted life year

${ }^{\text {a }}$ Costs of general internist/family doctor visit and nurse practitioner visit

${ }^{\mathrm{b}}$ Costs of gynecologist visit (only for women), psychiatrist visit, psychologist visit, and psychotherapist visit

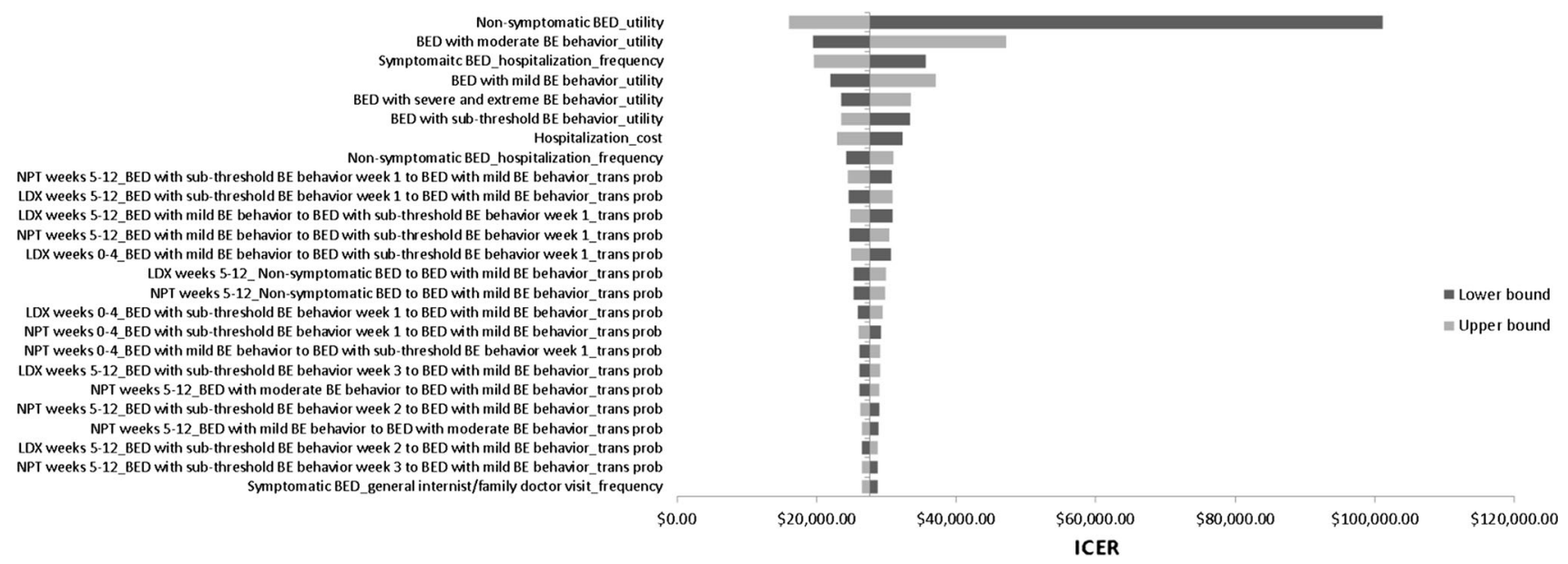

Fig. 2 Tornado diagram presenting the impact of changing the 25 most sensitive variables on the ICER. $B E$ binge eating, $B E D$ binge eating disorder, ICER incremental cost-effectiveness ratio, $L D X$

over one year [26]. If LDX were to treat $17.5 \%$ of patients diagnosed with BED, then the expected total annual budget would increase by US $\$ 1,069,080$ in the USA, which would be primarily due to the drug cost of LDX, as there would be expected healthcare utilization costs savings of US\$2,257,096 [26].

The findings of this cost-effectiveness analysis should be considered in the light of the following limitations:

- Although, Markov health states were constructed in accordance with the DSM-5 criteria, health states were solely based on the frequency of binge eating episodes. Other disease severity symptoms such as psychological distress or obsessive/compulsive behavior were not taken into account.
Lisdexamfetamine dimesylate, $N P T$ no pharmacotherapy, trans prob transition probability

- Patients treated with LDX were assumed to take the drug for 12 weeks in accordance with the two phase III pivotal clinical trials; at this time long-term efficacy data were not available to establish treatment duration.

- Steady relapse was assumed after LDX treatment was completed; no data exist on recurrence and remission of BED after the discontinuation of LDX therapy.

- It is worth noting that cost of hospitalization was not specific to BED, but to International Classification of Diseases-Version 9 (ICD-9) 307 'special symptoms or syndromes not elsewhere classified'. The reason for this was that BED is not recognized in ICD, which is the official system of assigning codes to diagnoses in the USA, BED can be coded under 307.5 'eating disorder, 
Fig. 3 Cost-effectiveness acceptability curve of the probabilistic sensitivity analysis

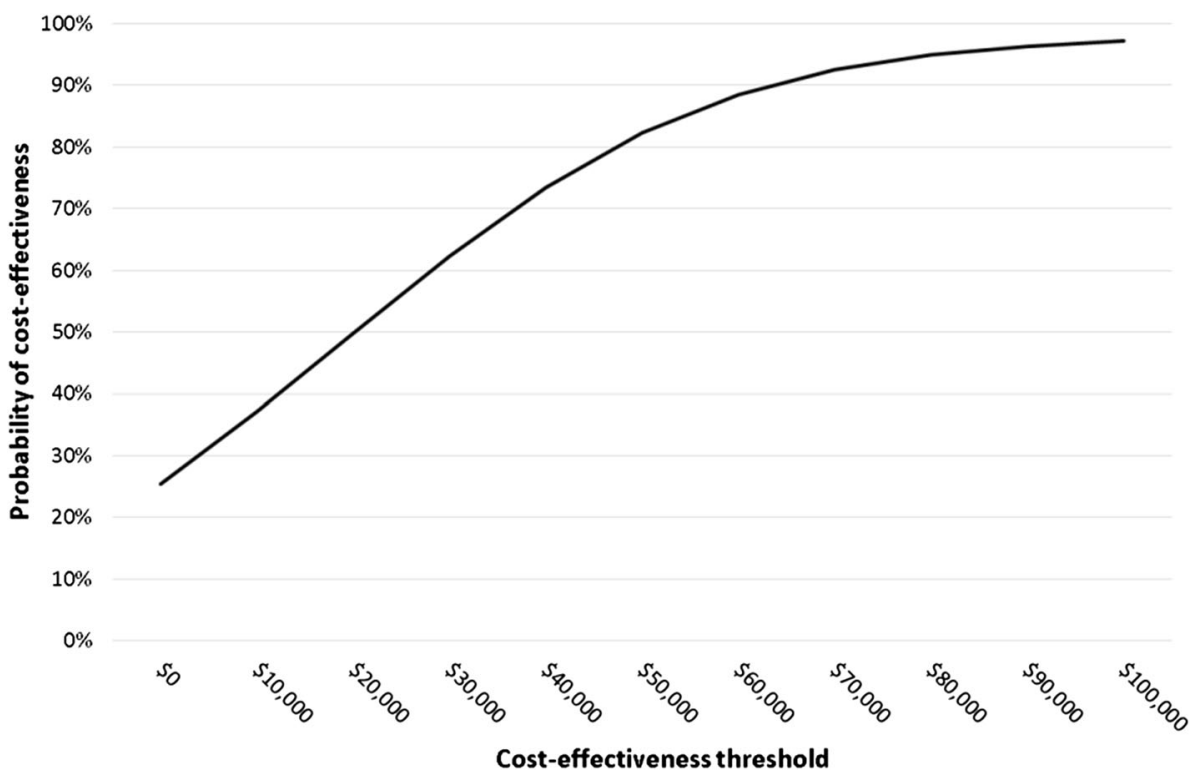

unspecified' (EDNOS); however, cost data for 4-digit ICD codes are not available in Medical Expenditure Panel Survey (MEPS).

- The present study might be cautiously generalized to real-world setting, since effectiveness parameters, such as medication adherence and discontinuation rates, can be considerably different. We chose not to account with medication adherence in this analysis as the majority of subjects in the pivotal clinical trials were adherent to LDX [18] and no real-world data on adherence to LDX in BED exist.

\section{Conclusions}

Treatment of BED with LDX showed an increase in QALYs at an acceptable cost and is considered cost effective at the commonly used willingness-to-pay threshold (US\$50,000) in the USA. Based on the available evidence the current model focused on short-term benefits only; however, additional scientific evidence supporting long-term benefits may further validate the health economic results.

Acknowledgments Editorial assistance in the form of proofreading, and copyediting was provided by Complete Healthcare Communications, Inc. (CHC, Chadds Ford, PA, US).

\section{Compliance with Ethical Standards}

Funding This study was financially supported by Shire (Wayne, PA, US).

Conflict of interest statement TA, BN, and ZV are employees of the Syreon Research Institute (Budapest, Hungary) which received funding for this research from Shire Development LLC. MP was employee and stock holder of Shire when the study was completed. JL is an employee of the University of Montreal (Montreal, Canada) with funding provided by Shire Development LLC.

Author contribution TA was involved in model design, analysis and interpretation of data, model programming, interpretation of model results, and writting the manuscript. MP was involved in model design, interpretation of model results, the review of all versions of the manuscript. BN was invloved in model design and programming, interpretation of model results, and the review of all versions of the manuscript. JL was involved in model design, model review, and the review of all versions of the manuscript. $\mathrm{ZV}$ was involved in model design, statistical analysis, model programming, interpretation of model results, and the review of all versions of the manuscript. All authors approved the final version of the manuscript.

Open Access This article is distributed under the terms of the Creative Commons Attribution-NonCommercial 4.0 International License (http://creativecommons.org/licenses/by-nc/4.0/), which permits any noncommercial use, distribution, and reproduction in any medium, provided you give appropriate credit to the original author(s) and the source, provide a link to the Creative Commons license, and indicate if changes were made.

\section{References}

1. American Psychiatric Association. Diagnostic and statistical manual of mental disorders. 5th ed. Arlington: American Psychiatric Association; 2015.

2. Agh T, Kovacs G, Pawaskar M, Supina D, Inotai A, Voko Z. Epidemiology, health-related quality of life and economic burden of binge eating disorder: a systematic literature review. Eat Weight Disord. 2015;20:1-12.

3. Hudson JI, Hiripi E, Pope HG Jr, Kessler RC. The prevalence and correlates of eating disorders in the National Comorbidity Survey Replication. Biol Psychiatry. 2007;61:348-58.

4. Kessler RC, Berglund PA, Chiu WT, Deitz AC, Hudson JI, Shahly V, Aguilar-Gaxiola S, Alonso J, Angermeyer MC, Benjet 
C, Bruffaerts R, de Girolamo G, de Graaf R, Maria Haro J, Kovess-Masfety V, O’Neill S, Posada-Villa J, Sasu C, Scott K, Viana MC, Xavier M. The prevalence and correlates of binge eating disorder in the World Health Organization World Mental Health Surveys. Biol Psychiatry. 2013;73:904-14.

5. Preti A, Girolamo G, Vilagut G, Alonso J, Graaf RD, Bruffaerts R, Demyttenaere K, Pinto-Meza A, Haro JM, Morosini P. The epidemiology of eating disorders in six European countries: results of the ESEMeD-WMH project. J Psychiatr Res. 2009;43:1125-32.

6. Swanson SA, Crow SJ, Le Grange D, Swendsen J, Merikangas KR. Prevalence and correlates of eating disorders in adolescents. Results from the national comorbidity survey replication adolescent supplement. Arch Gen Psychiatry. 2011;68:714-23.

7. Wilfley DE, Wilson GT, Agras WS. The clinical significance of binge eating disorder. Int J Eat Disord. 2003;34:S96-106.

8. Mond JM, Hay PJ, Rodgers B, Owen C. Health service utilization for eating disorders: findings from a community-based study. Int J Eat Disord. 2007;40:399-408.

9. American Psychiatric Association. American Psychiatric Association, practice guideline for the treatment of patients with eating disorders, third edition. Am J Psychiatry. 2006;163:S4-54.

10. Iacovino JM, Gredysa DM, Altman M, Wilfley DE. Psychological treatments for binge eating disorder. Curr Psychiatry Rep. 2012;14:432-46.

11. Hudson JI, McElroy SL, Raymond NC, Crow S, Keck PE Jr, Carter WP, Mitchell JE, Strakowski SM, Pope HG Jr, Coleman BS, Jonas JM. Fluvoxamine in the treatment of binge-eating disorder: a multicenter placebo-controlled, double-blind trial. Am J Psychiatry. 1998;155:1756-62.

12. Leombruni P, Piero A, Lavagnino L, Brustolin A, Campisi S, Fassino S. A randomized, double-blind trial comparing sertraline and fluoxetine 6-month treatment in obese patients with Binge Eating Disorder. Prog Neuropsychopharmacol Biol Psychiatry. 2008;32:1599-605.

13. McElroy SL, Hudson JI, Malhotra S, Hudson JI, Malhotra S, Welge JA, Nelson EB, Keck PE Jr. Citalopram in the treatment of binge-eating disorder: a placebo-controlled trial. J Clin Psychiatry. 2003;64:807-13.

14. Guerdjikova AI, McElroy SL, Winstanley EL, Nelson EB, Mori N, McCoy J, Keck PE Jr, Hudson JI. Duloxetine in the treatment of binge eating disorder with depressive disorders: a placebocontrolled trial. Int J Eat Disord. 2012;45:281-9.

15. Guerdjikova AI, McElroy SL, Welge JA, Nelson E, Keck PE, Hudson JI. Lamotrigine in the treatment of binge-eating disorder with obesity: a randomized, placebo-controlled monotherapy trial. Int Clin Psychopharmacol. 2009;24:150-8.

16. McElroy SL, Hudson JI, Capece JA, Beyers K, Fisher AC, Rosenthal NR. Topiramate for the treatment of binge eating disorder associated with obesity: a placebo-controlled study. Biol Psychiatry. 2007;61:1039-48.

17. Reas DL, Grilo CM. Review and meta-analysis of pharmacotherapy for binge-eating disorder. Obesity (Silver Spring). 2008;16:2024-38.

18. McElroy SL, Hudson J, Ferreira-Cornwell MC, Radewonuk J, Whitaker T, Gasior M. Lisdexamfetamine dimesylate for adults with moderate to severe binge eating disorder: results of two pivotal phase 3 randomized controlled trials. Neuropsychopharmacology. 2015. doi:10.1038/npp.2015.275.

19. Drummond MF, Sculpher MJ, Torrance GW, O’Brien B, Stoddart G. Methods for the economic evaluation of health care programmes. 3rd ed. Oxford: Oxford University Press; 2005.

20. US Census Bureau. National population projections: 2012 to 2060. Middle series. 2012. http://www.census.gov/population/ projections/data/national/2012/downloadablefiles.html. Accessed 3 Sept 2014.

21. Medical Expenditure Panel Survey. 2012. http://meps.ahrq.gov/ mepsweb/about_meps/survey_back.jsp. Accessed 6 Jan 2015.

22. World Bank. (2014) Inflation, GDP deflator (annual \%). 2014. http://databank.worldbank.org/. Accessed 14 Oct 2014.

23. Gray AM, Clarke PM, Wolstenholme JL, Wordsworth S. Applied methods of cost-effectiveness analysis in health care. Oxford: Oxford University Press; 2011.

24. Briggs A, Claxton K, Sculpher M. Decision modelling for health economic evaluation. Oxford: Oxford University Press; 2006.

25. Weinstein MC. How much are Americans willing to pay for a quality-adjusted life year? Med Care. 2008;46:343-5.

26. Agh T, Pawaskar M, Nagy B, Szilberhorn L, Voko Z. Budget impact analysis of introducing lisdexamfetamine dimesylate for the treatment of binge eating disorder in the United States. Value Health. 2015;18:A408. 